\title{
О МЕХАНИЗМЕ ФУНКЦИОНИРОВАНИЯ СИСТЕМЫ СТРАХОВАНИЯ ВКЛАДОВ В ЗАРУБЕЖНОЙ ПРАКТИКЕ
}

\author{
(C) 2021 Цибульникова Валерия Юрьевна \\ кандидат экономических наук, доцент, заведующий кафедрой экономики \\ Томский государственный университет систем управления и радиоэлектроники, Россия, Томск \\ E-mail: tuv82@bk.ru
}

\section{(c) 2021 Земцов Анатолий Анатольевич}

доктор экономических наук, профессор, профессор кафедры экономики, социологии, политологии и права

Сибирский государственный медицинский университет, Россия, Томск

E-mail: fbd1997@yandex.ru

Функционирование системы страхования вкладов неоднократно обсуждалось в публикациях отечественных исследователей. При этом такие задачи как проектирование системы страхования вкладов, способствующей развитию компенсационного механизма в нескольких направлениях финансового рынка, решение проблемы морального риска, требуют дополнительного изучения. В рамках данной статьи представлен обзор зарубежных публикаций, который раскрывает проблемное поле в части функционирования системы страхования вкладов в разных странах и обозначает фундаментальные взгляды на указанные выше задачи. Данный обзор позволяет раскрыть базу, необходимую для дальнейших исследований компенсационного механизма в банковской и инвестиционной сферах.

Ключевые слова: банк, система страхования вкладов, «бегство» вкладчиков, вкладчик, моральный риск, дизайн системы страхования вкладов.

\section{Введение}

Страхование вкладов широко распространено во всем мире и является неотъемлемой частью системы финансовой безопасности банковской системы. В России после долгого периода обсуждений и согласований система страхования вкладов была внедрена только в 2004 г. И основной проблемой российского исследовательского поля стали вопросы повышения доверия к банковской системе и адаптация зарубежного опыта к особенностям отечественной экономики. В связи с этим специфика исследовательского контекста российских ученых в основном лежит в плоскости обсуждения эффективности системы страхования вкладов, оптимальной суммы взносов участников, определения показателей рискованности банков и в сфере обсуждения страхового механизма системы.

В то же время в зарубежной литературе после кризиса 2008 г. стал активно обсуждаться вопрос о влиянии страхования вкладов на финансовую стабильность банковской системы в целом, и о стоимости морального риска, связанного с уровнем государственного вмешательства в этот процесс. В обзорах российских ученных про- блема морального риска рассматривалась поверхностно, также как и задачи проектирования системы страхования вкладов под современный контекст развития банковского сектора.

В связи с этим в данной статье выполнен теоретический обзор основных зарубежных публикаций по страхованию вкладов. Целью исследования является изучение различных моделей систем страхования вкладов, и выявление ключевых факторов, которые могут способствовать повышению эффективности российского компенсационного механизма. В некоторых источниках утверждается, что внимательное отношение к этапу планирования и разработки системы страхования вкладов под особенности банковской системы страны может оказать существенное влияние на то, насколько хорошо схемы страхования вкладов работают на практике.

Проблема доверия системе и «бегство» вкладчиков

Одна из основных задач, для решения которой создавалась система страхования вкладов, это снижение оттока вкладчиков из банковского сектора в период экономической нестабиль- 
ности. Необходимо понять, как проектирование системы страхования вкладов повышает доверие вкладчиков к финансовому институту и есть ли зависимость между уровнем оттока клиентов из банка и уровнем развития компенсационного механизма.

Если существенная часть вкладчиков снимет свои деньги одновременно, то банки не смогут вкладывать средства в долгосрочные активы и поддерживать ликвидность. В тоже время снижение стоимости активов, находящихся в распоряжении банков, может вызвать вывод вкладчиками средств из банка. Это в западной терминологии называется «бегством» вкладчиков из банка, которое проявляется как массовое одномоментное изъятие вкладчиками средств с банковских вкладов на фоне боязни скорого банкротства банка.

Поскольку срочные вклады выплачиваются по принципу ФИФО (кто вложил средства раньше, получает их первым), а снижение стоимости активов банка происходит внезапно и в значительном масштабе, то в этом случае вывод вкладчиками своих средств оправдан, поскольку вкладчики последней очереди понимают, что они могут ничего не получить, если у банка закончатся резервы.

Согласно модели Даймонда и Дыбвига [16], если вкладчики полагают, что произойдет отток вкладов, это провоцирует реальное «бегство» вкладчиков из банка, поскольку они не хотят оказаться последними в очереди. В итоге банк будет ликвидировать долгосрочные активы и нести большие финансовые потери. Если же вкладчики считают, что они получат свои деньги обратно из страхового фонда вне зависимости от того, что делают другие вкладчики и последние ли они в очереди, то у них, как правило, отсутствуют стимулы выводить свои средства. Банку в таком случае не нужно ликвидировать долгосрочные активы, и он остается платежеспособным.

Важно отметить, что эффективность страхования вкладов в модели Даймонда-Дыбвига в решающей степени опирается на предположение о том, что вкладчики полностью уверены в системе страхования вкладов. Если вкладчики считают, что существует даже небольшая вероятность того, что у страховщика закончатся средства, то инвесторы начинают выводить свои вклады. Все страховые схемы недофинансируются в том смысле, что у них нет средств для полного покрытия всех потенциальных потерь.

Но, как правило, есть ожидания, что государство обеспечит полную поддержку, если такая необходимость возникнет. Это требует от государства политической воли и, что более важно, экономических ресурсов для вмешательства и финансирования потерь вкладчиков. В странах с развитым банковским сектором и децентрализованными государственными финансами вмешательство государства наряду с недофинансированием системы страхования вкладов не всегда является адекватным вариантом. Так во время финансового кризиса 2008 г. произошло несколько эпизодов, которые поставили под угрозу доверие к схемам страхования вкладов в ряде стран.

Если банкротства банков являются результатом нехватки ликвидности, а не результатом их неплатежеспособности, то целесообразно предположить, что аналогичную функцию может выполнять центральный банк, как кредитор последней инстанции. В большинстве стран центральным банкам (далее ЦБ) разрешается предоставлять банковскому сектору временную ликвидность для устранения краткосрочных проблем из-за ухода вкладчиков. Если ЦБ обладает возможностями и авторитетом выступать кредитором последней инстанции, то сама готовность ЦБ к этому может иметь стабилизирующий эффект без необходимости прямого вмешательства. Однако на практике трудно отличить проблемы ликвидности от проблем, связанных с платежеспособностью.

В ряде других исследований модель Даймонда-Дыбвига была дополнена внедрением банковского управления рисками. Банки в модели Даймонда-Дыбвига инвестируют в безрисковые активы. Введение в модель инвестиций в рискованные активы при наличии гарантий сохранности вкладов порождает проблему «морального риска», который означате принятие банком более рискованных сделок и операций, выдачу кредитов ненадежным заемщикам в условиях того, что ответственность банка застрахована государством. Следовательно проектирование современной системы страхования вкладов должно минимизировать фактор «морального риска».

Учитывая значительные экономические издержки, связанные с банковским кризисом, страхование вкладов, в той мере, в какой оно препятствует изъятию средств из банков, мо- 
жет быть весьма ценным. Например, Мартин, Пьюри, Юфер [25] выявили, что незастрахованные вкладчики бегут из банков после плохих новостей, и что гарантирование вкладов снижает их отток, обеспечивая необходимую банку ликвидность. Дженсен, Йоханнес и Шеридан [22] показали, что реформа датской банковской системы, ограничившая страховое покрытие, вызвала снижение вкладов на 50\% выше страхового лимита. Делонг и Сандерс [12] выявили, что вкладчики были менее склонны выводить свои вклады из более слабых банков после введения в США федерального страхования вкладов с фиксированной суммой страхового покрытия. А. Ангкинан [6], изучив данные о 47 кризисах в 35 странах в 1970-2003 гг., выяснила, что издержки на преодоление банковских кризисов были ниже для стран с высоким уровнем развития системы страхования вкладов.

Помимо снижения возможности банковских кризисов, страхование вкладов дает и другие косвенные экономические выгоды. Страхование вкладов может способствовать усилению конкуренции и повышению финансовой стабильности за счет снижения системного риска [5]. Без явной гарантии вкладчики поощряются к тому, чтобы вкладывать свои сбережения в очень крупные банки, которые, скорее всего, будут диверсифицировать свои риски и риск банкротства которых минимален.

Страхование вкладов может выровнять систему и позволить небольшим банкам привлекать вклады и тем самым способствовать усилению конкуренции. Страхование вкладов также может помочь частным банкам конкурировать с госбанками, которые обычно пользуются явными или неявными гарантиями со стороны правительства, а также с иностранными банками, получающими страховое покрытие от своей страны.

\section{Проблема «морального риска» и эконо- мические издержки системы}

Наличие гарантий страхования вкладов привносит доверие на рынок, но в то же время искажает намерения как руководителей банков, так и вкладчиков, что приводит к проблеме морального риска. Во-первых, страхование вкладов дает застрахованным банкам стимулы брать на себя более рискованные обязательства, так как экономическую прибыль от более высокого принятия рисков получает банк, а убытки компенсируются через фонд страхования вкладов.
Во-вторых, поскольку вкладчики защищены, когда банк терпит убытки, их стимул следить за финансовым состоянием своего банка значительно снижается.

Термин «моральный риск» пришел из индустрии страхования с идеей, что страхование часто искажает поведение потребителя. В контексте банковского дела эти искажения усиливаются. Частное страхование, как правило, страхует только от потерь, которые четко определены, и исключает некоторые виды риска из сферы охвата, например исключение самоубийств из страхования жизни. Эти исключения обеспечивают стимулы для предотвращения самих рисковых ситуаций. Страхование вкладов в этом отношении не является страхованием как таковым, это скорее гарантия защиты от убытков, возникающих в результате любого вида банкротства банка, независимо от его причины. Исключения отсутствуют поскольку важно обеспечить доверие к банковскому сектору в целом.

В некоторых исследованиях рассматриваются экономические издержки страхования вкладов. В [13] Демиргук-Кунт и Детрагиах выявили, что реализация прямого страхования вкладов страной приводит к большей вероятности возникновения банковского кризиса. Другие исследования показали, что реализация страхования вкладов снижает рыночную дисциплину, приводящую к большей рискованности банков. Нье и Бауманн [28] показали, что внедрение системы страхования вкладов снижает совокупный объем капитала, который поддерживают банки. Демиргук-Кунт и Хуизинга [14] показывают, что страхование вкладов снижает чувствительность ставок по депозитам к изменениям банковского риска, и этот эффект проявляется больше для систем страхования с более высоким порогом возмещения, широким охватом видов вкладов, для систем, управляемых государством.

Каломирис и Чен [8, 9], изучив большой перечень стран, обнаружили, что внедрение систем страхования вкладов приводит к более высоким коэффициентам «заемный капитал к активам» и «заемный капитал к акционерному капиталу». Это провоцирует более частые дефолты банков в результате повышения риска потери активов и увеличения заемных средств. Аналогичным образом отказ от страхования вкладов повышает рыночную дисциплину. Гропп, Груэндл и Гэттлер [20] показывают, что после того, как в 2001 году в Германии были сняты государственные гаран- 
тии для сберегательных банков, они отказали в выдаче кредитов своим самым рискованным заемщикам и отказались от рисковых долговых инструментов.

Однако не все исследования отмечают рост банковских рисков. Например, Уилок, Уилсон [30], Алстон и др. [2] показали, что страхование вкладов не привело к росту банкротств банков в США. Мартинес-Перия и Шмаклер [26], используя данные из Аргентины, Чили и Мексики за 1980-е и 1990-е годы, обнаружили, что вкладчики выводят средства и требуют высоких процентных ставок во время кризиса, обеспечивая тем самым рыночную дисциплину. Они связывают это с тем, что уровень доверия к тем схемам страхования вкладов был низким.

Хотя страхование вкладов может повысить моральный риск и сделать финансовые системы более уязвимыми к кризисам во времена стабильности, оно также может повысить доверие вкладчиков и снизить вероятность массового бегства вкладчиков из банков в кризисные периоды. Чистый эффект от функционирования системы страхования вкладов, защиты от риска банков и поддержания стабильности зависит от того, перевешивают ли выгоды от страхования вкладов его издержки.

Некоторые исследования пытались определить, доминирует ли эффект «морального риска» над «эффектом стабильности» страхования вкладов [21]. Нгалава, Тчана и Вьеги [27] утверждают, что если внедрение системы страхования вкладов связано в большей степени с неплатежеспособностью банков, чем с оттоком вкладов из банков, то эффект морального риска доминирует, и издержки, связанные с моральным риском, перевешивают преимущества от страхования вкладов.

В $[3,4,11]$ изучено влияние страхования вкладов на системный риск банка до и после мирового финансового кризиса. Авторы считают, что более «щедрые» схемы страхования вкладов повышают банковский риск и снижают системную стабильность в некризисные годы. А во время кризисов, наоборот, банковский риск ниже, а стабильность системы выше в странах, где были приняты более высокие суммы возмещения. При этом общий эффект от страхования вкладов остается отрицательным.

Есть и ряд других факторов системы страхования вкладов, которые оказывают влияние на системные риски. Во-первых, политика банка может быть направлена на сдерживание рисков. Банки смогут получать экономическую выгоду от своей репутации и лояльных отношений с клиентами. Кроме того, банковские управляющие, как правило, получают существенную часть своего дохода, зависящую от деятельности их банка, что может помочь смягчить влияние страхования вкладов на принятие рисков.

Во-вторых, системы страхования вкладов должны быть априори надежными, чтобы предотвращать бегство вкладчиков из банков. А поскольку они не финансируются в полном объеме, то вкладчики стремятся выбрать более надежные банки, снижая эффект морального риска.

В-третьих, мониторинг со стороны заемщиков, которые не подпадают под систему страхования вкладов, может дисциплинировать рынок и сдерживать чрезмерный риск, который могут брать на себя банки $[18,25]$.

В-четвертых, банки, которые слишком велики, чтобы обанкротиться, могут извлечь выгоду из неявных государственных гарантий по незастрахованному долгу. Исследования показывают, что риск не полностью учтен в стоимости незастрахованного финансирования для крупных банков, которые признаны системно важными [1]. Ожидание поддержки приводит к проблемам морального риска в виде чрезмерного принятия рисков, аналогично тем, которые связаны со страхованием вкладов. Таким образом, более крупные банки могут не иметь рыночной дисциплины независимо от того, защищает ли имеющаяся страховая схема вкладчиков или нет.

Наконец, та форма, в которой спроектирована и внедрена система страхования вкладов в разных странах весьма различна.

Институциональная среда и проектирование системы

Существуют исследования, которые говорят о том, что хорошо продуманная схема страхования вкладов в сочетании с эффективным регулированием и надзором может обеспечить стабильность при минимизации некоторых искажений, вносимых страхованием вкладов. В частности, две ключевые особенности проектирования систем страхования вкладов: лимиты покрытия и ценообразование на основе рисков, могут оказать важное влияние на то, насколько хорошо функционирует система страхования вкладов. 
Ограничения по страховому покрытию широко распространены в страховой отрасли для снижения и контроля рисков. Во-первых, существуют ограничения по видам учреждений, которые включаются в системы страхования. Как правило, страхованием вкладов охвачены только коммерческие банки. В некоторых странах также охвачены потребительские кооперативы, брокерские и дилерские фирмы. Существуют также различия между странами в том, распространяется ли защита на филиалы и дочерние компании местных банков или на местные филиалы иностранных банков. Независимо от видов охватываемых учреждений важно предусматривать членство всех организаций в системе страхования вкладов обязательным.

Во-вторых, существуют ограничения по видам вкладов, которые покрываются системой. В большинстве стран гарантированы только срочные вклады и вклады до востребования. Во время финансового кризиса ряд стран расширили охват, включив в него банковские обязательства, помимо срочных вкладов. Таким примером является Ирландия, которая ввела общую гарантию по всем банковским обязательствам, включая межбанковские депозиты и субординированный долг.

B-третьих, существуют ограничения на максимальную сумму вкладов, которые застрахованы.В этих пределах между странами наблюдается большое различие [15]. В США гарантированная предельная сумма (на одного вкладчика, на банк) была увеличена с 40 тыс. долларов до 100 тыс. долларов в 1980 году. Этот лимит был повышен до 250 тыс. долларов в 2008 году, чтобы восстановить доверие к банковской системе во время кризиса. Определить оптимальное покрытие для страхования вкладов сложно. С одной стороны, покрываемые суммы должны быть достаточно высокими для предотвращения массового оттока вкладов из банков, но с другой стороны, слишком широкий охват может снизить эффективную рыночную дисциплину. Международный валютный фонд в качестве общего правила для установления соответствующих лимитов по страхованию вкладов рекомендует покрытие на человека, которое примерно в один-два раза превышает ВВП на душу населения. Эмпирические исследования показывают, что более «щедрые» схемы страхования вкладов с точки зрения охвата чаще страдают от морального риска.
Например, по некоторым оценкам [28], страны, где лимит страхования вкладов в четыре раза превышает ВВП на душу населения, в пять раз чаще страдают от банковского кризиса, чем страны, где этот лимит меньше размера ВВП на душу населения. Покрытие должно исключать крупных вкладчиков, держателей субординированных долгов и банков-корреспондентов, убедив их, что их средства находятся под угрозой. Это будет стимулировать их к обеспечению эффективного контроля за своим капиталом в дополнение к официальному надзору за деятельностью учреждений.

Взимание с банков взносов с поправкой на риск - еще один способ смягчить моральный риск. Взносы для обеспечения системы страхования вкладов могут быть основаны на фиксированной ставке или они могут быть основаны на риске, который каждый банк представляет для системы. По сравнению с премиями с фиксированной ставкой премии с поправкой на риск побуждают застрахованные банки снижать принимаемые на себя риски.

Страхование вкладов с поправкой на риски особенно распространено в странах с высоким уровнем дохода (около 78\%). Для стран со средним и низким уровнем доходов эта доля ниже $40 \%$. Несмотря на то, что страхование вкладов с поправкой на риск обеспечивает снижение банками принимаемых рисков, определить размер взноса, который следует вносить банкам в систему, сложно. Как правило, для определения ставки взносов используются оценочные рейтинги банков, достаточность капитала, ликвидность и качество активов. FDIC, например, присваивает банкам несколько категорий риска на основе уровня капитализации банков и надзорного рейтинга, а затем начисляет разную страховую премию для каждой категории риска. Эмпирические данные говорят о том, что премии, скорректированные на риск, работают лучше, чем премии с фиксированной ставкой, снижая чрезмерный риск, принимаемый банками [19].

Еще один способ исправить искажения, вызванные страхованием вкладов, - дополнить его надежным надзором и регулированием банковской системы. Более жесткие требования к капиталу - один из способов помешать банкам брать на себя чрезмерный риск. Купер и Росс [10] показывают, что дополнительные требования к капиталу могут снизить чрезмерные стимулы к 
принятию рисков банками в рамках страхования вкладов, но не полностью устраняют проблему морального риска. Барт, Каприо и Лесин [7] показывают, что жесткое регулирование капитала оказывает лишь незначительное воздействие на снижение негативного влияния страхования вкладов на хрупкость банков.

Общественный мониторинг и надзор также могут снизить негативные последствия страхования вкладов в части принятия рисков. Эффективный контроль требует от властей полномочий принимать упреждающие меры до возникновения проблем и принимать своевременные меры по исправлению положения в случае их возникновения. Важно также, чтобы надзорные органы обладали полномочиями для быстрого и эффективного решения проблем, связанных с несостоятельными банками. Неспособность государственных структур своевременно закрыть банки может значительно увеличить ответственность страховщиков, так как у банков есть стимулы взять на себя еще больший риск, когда они близки к дефолту [23, 29]. Так в [3] Демиург-Кунт показал, что улучшение банковского надзора может помочь смягчить неблагоприятные последствия страхования вкладов, в то время как низкое качество банковского надзора усугубляет негативное влияние страхования вкладов на стабильность банков.

Частный мониторинг со стороны участников рынка, таких как незастрахованные кредиторы, акционеры и рейтинговые агентства, также может снизить неблагоприятные последствия страхования вкладов. Строгие правила раскрытия информации, независимые внешние проверки и доступность государственных и частных рейтинговых агентств - все это повышает прозрачность и позволяет повысить дисциплину участников рынка [17].

\section{Заключение}

Страхование вкладов в настоящее время является признанной и широко принятой политикой содействия стабильности банковского сектора. В литературе прочно укоренилось мнение о том, что всеобщее страхование вкладов может обеспечить уверенность вкладчиков и предотвратить массовые изъятия вкладов из банков, но оно также влечет за собой непреднамеренные последствия, побуждающие банки брать на себя чрезмерный риск. Эмпирические данные указывают на важность конструктивных особенностей системы и показывают, что плохо разработанные схемы могут повысить вероятность того, что страна столкнется с банковским кризисом. Важно, чтобы схемы страхования вкладов включали функции, помогающие банкам интернализировать риск. Помимо конкретных конструктивных особенностей, страхование вкладов, дополняемое более строгими правилами регулирования капитала и системой, в рамках которой руководители имеют право принимать оперативные меры по исправлению положения, на практике, как правило, функционирует более эффективно.

Важно также, чтобы страны культивировали условия, в которых частные участники рынка, такие как крупные незастрахованные вкладчики, акционеры и другие кредиторы, имели правильный набор стимулов для мониторинга банков, в которые они инвестируют. В странах, в которых отсутствуют прочные институциональные условия, всеобщее страхование вкладов в итоге может принести больше вреда, чем пользы с точки зрения повышения финансовой стабильности. Подводя итог, можно сказать, что влияние страхования вкладов может быть непредсказуемым. Будет ли это выгодно или вредно для страны, зависит от того, насколько хорошо она разработана и управляется.

\section{Библиографический список}

1. Acharya V. V., Anginer D., Warburton A. J. The end of market discipline? Investor expectations of implicit government guarantees. Munich Personal RePEc Archive; 2016. URL: https://mpra.ub.uni-muenchen.de/79700.

2. Alston L. J., Grove W.A., WheelockD. C.. Why do banks fail? Evidence from the 1920s. Explorations in Economic History. 1994; 31(4): 409-431.

3. Anginer D., Demirgüç-Kunt A., Bank capital and systemic stability, The World Bank, Washington, DC. Policy Research Working Paper № 6948. 2014; URL: http://documents1.worldbank.org/curated/en/599901468326366375/pdf/ WPS6948.pdf.

4. Anginer D., Demirgüç-Kunt A., Huizinga H., Ma K. Corporate Governance and Bank Risk Taking. World Scientific Book Chapters, in: Asli Demirgüç-Kunt \& Douglas D Evanoff \& George G Kaufman (ed.), The Future of Large, Internationally Active Banks. 2016; chapter 21, pages 349-370, World Scientific Publishing Co. Pte. Ltd. 
5. Anginer D., Demirguc-Kunt A., Zhu M. How does competition affect bank systemic risk?. Journal of Financial Intermediation. 2014; 23(1): 1-26.

6. Angkinand, A.P. Banking regulation and the output cost of banking crises. Journal of International Financial Markets, Institutions and Money. 2009; 19(2): 240-257.

7. Barth J.R., Caprio G.J., Levine R. Bank regulation and supervision: what works best?. Journal of Financial Intermediation. 2004; 13: 205-248.

8. Calomiris C.W., Chen S. The spread of deposit insurance and the global rise in bank leverage since the 1970s. Working Paper, Columbia Business School. 2016.

9. Calomiris C.W., Jaremski M. Deposit insurance: Theories and facts. Annual Review of Financial Economics. 2016; 8: $97-120$.

10. Cooper R., Ross T. W. Bank runs: Deposit insurance and capital requirements. International Economic Review. 2002; 43(1): 55-72.

11. Cull R., Senbet L. W., Sorge M. Deposit insurance and financial development. Journal of Money, Credit and Banking. 2005; pp. 43-82.

12. DeLong G., Saunders A. Did the introduction of fixed-rate federal deposit insurance increase long-term bank risktaking? Journal of Financial Stability. 2011; 7(1):19-25.

13. Demirgüç-Kunt A., Detragiache E. Does deposit insurance increase banking system stability? An empirical investigation. Journal of Monetary Economics. 2002; 49(7): 1373-1406.

14. Demirgüç-Kunt A., Huizinga H. Market discipline and deposit insurance. Journal of Monetary Economics. 2004; 51(2): 375-399.

15. Demirgüç-Kunt A., Kane E., Laeven L. Deposit insurance around the world: A comprehensive analysis and database. Journal of Financial Stability. 2015; 20: 155-183.

16. Diamond D.W., Dybvig P.H. Bank runs, deposit insurance, and liquidity. Journal of Political Economy. 1983; 91(3): 401-419.

17. Djankov S., McLiesh C., Shleifer A. Private credit in 129 countries. Journal of Financial Economics. 2007; 84(2): 299-329.

18. Flannery M.J., Sorescu S.M. Evidence of bank market discipline in subordinated debenture yields: 1983-1991. Journal of Finance. 1996; 51(4):1347-1377.

19. Fonseca A.R., González F. How bank capital buffers vary across countries: The influence of cost of deposits, market power and bank regulation. Journal of Banking \& Finance. 2010; 34(4): 892-902.

20. Gropp R., Gruendl C., Guettler A. The impact of public guarantees on bank risk- taking: Evidence from a natural experiment. Review of Finance. 2013; 18(2): 457-488.

21. Hoggarth G., Reis R., Saporta V. Costs of banking system instability: some empirical evidence. Journal of Banking \& Finance. 2002; 26(5): 825-855.

22. Iyer R., Jensen T., Johannesen N., Sheridan A. The run for safety: Financial fragility and deposit insurance. 2017. URL: https://www.hhs.se/contentassets/ba4aa0cf4eab4b8a8fc1695d40021216/lyer-rajkamal_the-run-for-safety_ financial-fragility-and-deposit-insurance.pdf.

23. Lucas D., McDonald R.L. An options-based approach to evaluating the risk of Fannie Mae and Freddie Mac. Journal of Monetary Economics. 2006; 53(1): 155-176.

24. Maccario A., Sironi A., Zazzara C. Credit Risk Models: An Application to Deposit Insurance Pricing. Università commerciale Luigi Bocconi. 2003. URL: https://www.fdic.gov/news/events/finance_banking/maccario.pdf.

25. Martin C., Puri M., Ufier A. On Deposit Stability in Failing Banks, Working Paper, Federal Deposit Insurance Corporation. 2017. URL: https://www.fdic.gov/bank/analytical/cfr/2018/wp2018/cfr-wp2018-02.pdf.

26. Martinez-Peria M.S., Schmukler S.L. Do depositors punish banks for bad behavior? Market discipline, deposit insurance, and banking crises. Journal of Finance. 2001; 56(3): 1029-1051.

27. Ngalawa H., Tchana F. T., Viegi N. Banking instability and deposit insurance: The role of moral hazard. Journal of Applied Economics. 2016; 19(2).

28. Nier E., Baumann U. Market discipline, disclosure and moral hazard in banking. Journal of Financial Intermediation. 2006; 15(3): 332-361.

29. Pyle D. H. Capital regulation and deposit insurance. Journal of Banking \& Finance. 1986; 10(2): 189-201.

30. Wheelock D.C., Wilson P.W. Can deposit insurance increase the risk of bank failure? Some historical evidence. Federal Reserve Bank of St. Louis Review. 1994; 76(3): 57. 